Gut, 1988, 29, 206-217

\title{
Colorectal cancer in ulcerative colitis: a cohort study of primary referrals from three centres
}

S N GYDE, P PRIOR, R N ALLAN, A STEVENS, D P JEWELL,

S C TRUELOVE, R LOFBERG, O BROSTROM, AND G HELLERS

From the Gastroenterology Unit, General Hospital, Birmingham, Cancer Epidemiology Research Unit, University of Birmingham, Gastroenterology Unit, John Radcliffe Hospital, Oxford, and Gastroenterology

Unit, South Hospital, Stockholm, Sweden

SUMmARY A retrospective cohort of 823 patients with ulcerative colitis who resided at the time of diagnosis in one of three defined geographical areas (West Midlands region, Oxford region, England and Stockholm County, Sweden) was assembled. The patients were first seen at named hospitals in these areas and the diagnosis of ulcerative colitis established within five years of onset of symptoms between 1945-1965. All patients were 15 years of age or more at onset of disease and were followed for a minimum of 17 years and a maximum of 38 years. Ninety seven per cent completeness of follow up was achieved. Examining the colorectal cancer risk in the series relative to the risk in the general population by standardised morbidity ratios, there was an eight fold increased risk of cancer in the series as a whole. Dividing the series by extent of colitis, extensive colitis patients showed a 19 fold increase in risk. A four fold increased risk was shown in the remainder of the series (left sided colitis, proctitis and extent unknown). Life table analyses in extensive colitis gave cumulative risks of $7 \cdot 2 \%$ (CI 3.6-10.8) at 20 years from onset of disease and 16.5\% (CI 9.0-24.0) at 30 years from onset. No significant effect of age at onset, sex or referral centre could be detected. Examination of the data by interval from onset to cancer and by actual age at development of cancer suggests that patients who develop colorectal cancer will do so in a distribution around 50 years of age independent of duration of disease in adult onset ulcerative colitis ( $>15$ years at onset of disease). An inverse relationship was shown between age at onset of disease and interval from onset of disease to cancer. Further age specific rates for cancer increased up to 50 years and decreased thereafter. These results suggest that extensive colitis patients have a genetic predisposition to colorectal cancer and that longstanding inflammation is not of primary importance in the initiation/promotion of cancer in this disease.

There is convincing evidence from previous studies that patients with ulcerative colitis have a higher incidence of colorectal cancer than the general population. ${ }^{1}$ This increased incidence occurs predominantly in patients with longstanding extensive colitis. Many previous estimates of the colorectal cancer incidence have been based on information drawn from hospital series of patients (Table 1$)^{2-8}$ and have given widely varying results. This variation is

Address for correspondence: Dr R N Allan, Gastroenterology Unit, General Hospital, Steelhouse Lane, Birmingham B4 6NH.

Received for publication 9 July 1987. more likely to be the result of selection biases inherent in these series rather than any real differences in the underlying cancer incidence of the groups under review.

\section{Methods}

SELECTION BIASES IN HOSPITAL SERIES

Ulcerative colitis is an uncommon condition (incidence $5-10 / 10^{5}$ population $)^{9-14}$ and therefore large groups of patients are only found in hospitals specialising in the treatment of the condition. Patients, 
Table 1 Cancerincidence in ulcerative colitis: hospital series

\begin{tabular}{|c|c|c|c|c|c|c|}
\hline \multirow[b]{2}{*}{ Authors and hospital series } & \multirow[b]{2}{*}{ Review period } & \multicolumn{2}{|l|}{ Cases } & \multicolumn{2}{|c|}{ Cancers } & \multirow{2}{*}{ Results } \\
\hline & & $\begin{array}{l}\text { Whole } \\
\text { series }\end{array}$ & $\begin{array}{l}\text { Extensive } \\
\text { colitis }\end{array}$ & $\begin{array}{l}\text { Whole } \\
\text { series }\end{array}$ & $\begin{array}{l}\text { Extensive } \\
\text { colitis }\end{array}$ & \\
\hline $\begin{array}{l}\text { de Dombal et al } \\
\text { General Infirmary, Leeds }\end{array}$ & $1952-1963$ & 428 & 210 & 8 & 8 & $\begin{array}{l}10 \text { years } 5 \% \\
20 \text { years } 21 \% \\
25 \text { years } 42 \%\end{array}$ \\
\hline $\begin{array}{l}\text { McDougall } \\
\text { Gordon Hospital, London }\end{array}$ & $1947-1963$ & 637 & 196 & 15 & 9 & $\begin{aligned} \text { Extensive colitis Observed } & =9, \mathrm{O} / \mathrm{E}=30 \\
\text { Expected } & =0 \cdot 3\end{aligned}$ \\
\hline $\begin{array}{l}\text { Edwards and Truelove } \\
\text { Radcliffe Infirmary, Oxford }\end{array}$ & $1938-1962$ & 624 & 236 & 22 & 17 & $\begin{array}{l}20 \text { years Whole series } 5 \cdot 5 \% \\
\qquad \begin{array}{l}\text { 1st attack } \\
(n=250)\end{array} \quad 12 \cdot 6 \%\end{array}$ \\
\hline $\begin{array}{l}\text { Greenstein et } a l^{5} \\
\text { Mount Sinai Hospital, New York }\end{array}$ & $1960-1976$ & 267 & NS & 26 & 21 & $\begin{array}{l}\text { Left sided colitis } O / E=8.6 \\
\text { Extensive colitis } O / E=26.5\end{array}$ \\
\hline $\begin{array}{l}\text { Prior et } \mathrm{al}^{7} \\
\text { Queen Elizabeth and General } \\
\text { Hospitals, Birmingham }\end{array}$ & $1944-1976$ & 676 & 462 & 35 & 35 & $\begin{array}{l}\text { Whole series }(68 \% \text { with extensive colitis) } \\
25 \text { years } 8 \% \\
30 \text { years } 20 \%\end{array}$ \\
\hline $\begin{array}{l}\text { Katzka et } a l^{8} \\
\text { Private practice, New York USA }\end{array}$ & $1955-1980$ & - & 106 & - & 4 & $\begin{array}{l}\text { Extensive colitis }>10 \text { years from onset } \\
\text { risk at } 11 \text { years } 7 \cdot 2 \%\end{array}$ \\
\hline
\end{tabular}

$\mathrm{O}=$ observed; $\mathrm{E}=$ expected; $\mathrm{NS}=$ not stated.

particularly with extensive disease, carry a significantly increased mortality throughout life. This increased mortality relates predominantly to the disease process itself in the early years, ${ }^{15-22}$ and in later years to colorectal cancer (Tables 1 and 2). ${ }^{2-8192223}$ Diagnosis of the disease is made by hospital referral and investigation. After diagnosis patients often undergo secondary and tertiary hospital referral to centres offering greater expertise in treatment which is known to reduce mortality particularly in patients undergoing major surgery. ${ }^{24}$ Selection biases inherent in any large specialist hospital series therefore include selection for (a) severity of disease, (b) colorectal cancer, and (c) a 'survivor population' effect.

Selection for severity of disease is due to secondary and tertiary referral. Selection for colorectal cancer occurs in cases where the symptoms of undiagnosed colorectal cancer complicating ulcerative colitis have been instrumental in initiating the referral. The 'survivor population' bias results from patients being referred to the specialist hospital late in the course of their disease. These patients are drawn from, but not representative of, all hospital referrals for ulcerative

Table 2 Cancer incidence in ulcerative colitis: population based series

\begin{tabular}{|c|c|c|c|c|c|c|}
\hline \multirow[b]{2}{*}{ Study } & \multirow[b]{2}{*}{ Review period } & \multicolumn{2}{|l|}{ Cases } & \multicolumn{2}{|c|}{ Cancers } & Results \\
\hline & & $\begin{array}{l}\text { Whole } \\
\text { series }\end{array}$ & $\begin{array}{l}\text { Extensive } \\
\text { colitis }\end{array}$ & $\begin{array}{l}\text { Whole } \\
\text { series }\end{array}$ & $\begin{array}{l}\text { Extensive } \\
\text { colitis }\end{array}$ & Cumulative cancer incidence \\
\hline $\begin{array}{l}\text { Hendriksen } \text { et }^{2} \mathrm{l}^{22} \\
\text { (Continuation of the Bonnevie study }{ }^{19} \text { in } \\
\text { Copenhagen County). All cases of ulcerative } \\
\text { colitis in Copenhagen County }\end{array}$ & $1960-1978$ & 783 & $\begin{array}{c}124 \text { (total } \\
\text { colitis) }\end{array}$ & 7 & $\begin{array}{l}2 \text { (total } \\
\text { colitis) }\end{array}$ & $\begin{array}{l}\text { Whole series } \\
10 \text { years } 0 \cdot 8 \% \\
15 \text { years } 1 \cdot 1 \% \\
18 \text { years } 1 \cdot 4 \%(\mathrm{CI} 0 \cdot 7-2.8) \\
\text { Median follow up } 6 \cdot 7 \text { years }\end{array}$ \\
\hline $\begin{array}{l}\text { Kewenter et al }{ }^{23} \\
\text { All cases in Goteburg City, Sweden diagnosed } \\
\text { 'shortly' after onset of disease }\end{array}$ & $1952-1975$ & NS & 234 & NS & 15 & $\begin{array}{l}15 \text { years } 9 \cdot 6 \%(\text { CI } 2 \cdot 6-16 \cdot 6) \\
20 \text { years } 24 \cdot 2 \%(\text { CI } 11 \cdot 0-37 \cdot 4) \\
\text { Median follow up } 6 \cdot 0 \text { years } \\
\text { Mean follow up } 8 \cdot 5 \text { years }\end{array}$ \\
\hline
\end{tabular}

$\mathrm{CI}=$ confidence intervals $; \mathrm{NS}=$ not stated. 
colitis, the selection being against inclusion of patients with a high risk of mortality - that is, patients with severe extensive disease or colorectal cancer. Although attempts can be made in the analysis to minimise bias towards severity of disease and selection into the series for cancer (by analysing by extent of disease and discarding any colorectal cancers diagnosed within one year of referral) the 'survivor population' bias remains an intractable problem. Any estimates, therefore, of the colorectal cancer incidence in ulcerative colitis based on specialist hospital series are of limited value. The estimates pertain only to that particular hospital series and cannot be extrapolated to refer to ulcerative colitis patients in general, as they are based on an unrepresentative sample.

\section{POPULATION BASED STUDY}

The epidemiological method of choice to determine the colorectal cancer incidence in ulcerative colitis would be to study all cases of ulcerative colitis diagnosed in a defined geographical area diagnosed over a defined time period. Only two studies of this type have been reported in the literature (Table 2). The Danish study by Hendriksen et al from Copenhagen County followed all patients diagnosed in the area between 1960-1978 (Table 2). ${ }^{22}$ Seven colorectal cancers were observed during the study period. In the Goteburg study from Sweden ${ }^{23}$ all cases of extensive colitis diagnosed in Goteburg City between 19511975 were followed up and 15 colorectal cancers were observed. Both these studies had a short median follow up (6.7 and 6.0 years respectively) as the cancer incidence does not appear to increase before 10 years from onset of disease (Tables 1 and 2). Longer follow up in these studies could provide reliable estimates of the cancer incidence in ulcerative colitis but as they stand, because of the short follow up and small numbers of cancers observed, estimates of the risk in extensive colitis have wide confidence limits (Table 1). ${ }^{22} 23$

PRESENT STUDY - DEFINITION OF A COHORT Population based studies such as those reported from Scandinavia are difficult to carry out except in countries with small and stable populations, and having relatively few hospitals serving the population. In England, most hospitals which are major referral centres for ulcerative colitis patients are situated in the larger cities (Table 1). They are in areas of high population densities with district general hospitals serving these populations and with large population movements in and out of the areas. To collect every case of ulcerative colitis diagnosed in a defined geographical area would therefore be extremely difficult.
In these circumstances an alternative method is needed of defining a cohort of patients representative of all patients diagnosed with ulcerative colitis from the general population in which to study the cancer incidence.

In this study it was decided to recruit only patients from defined geographical areas who were primary referrals to identified hospitals at or near onset of disease so eliminating secondary and tertiary referral biases in relation to specialist hospital series, but still enabling recruitment of patients from hospital series.

Several hospital series were needed to recruit a sufficiently large number of patients into the study to give worthwhile results. It was, in practice, extremely difficult to establish a large retrospective cohort on a multicentre basis because few hospitals (even those specialising in the treatment of the condition) kept listings by diagnostic group or clinical records for the necessary time period.

\section{PATIENTS}

\section{ENTRY CRITERIA}

A retrospective cohort of patients was assembled drawn from three centres: Birmingham, Oxford, and Stockholm.

Patients were recruited to the series if they fulfilled the following entry criteria: (1) They must have resided at the time of diagnosis in one of three defined geographical areas - West Midlands region, Oxford region (England), Stockholm County (Sweden). (2) They must have been seen first at named hospitals and a diagnosis of ulcerative colitis established within five years of onset of symptoms between the calendar years 1945-1965. (3) They must be 15 years of age or more at onset of disease.

Swedish patients fulfilling these entry criteria were drawn from a population study of all patients diagnosed in Stockholm County between the years 19451965.

The Oxford patients were drawn from a series of

Table 3 Total series by centre: extent of disease and major surgery

\begin{tabular}{|c|c|c|c|c|c|c|c|c|}
\hline & \multicolumn{4}{|c|}{ Birmingham Oxford } & \multicolumn{2}{|c|}{ Sweden } & \multicolumn{2}{|c|}{ Total } \\
\hline & $n$ & $\%$ & $n$ & $\%$ & $n$ & $\%$ & $n$ & $\%$ \\
\hline Extensive colitis & 210 & 80 & 99 & 38 & 177 & 59 & 486 & 59 \\
\hline Major surgery & 181 & 69 & 24 & 9 & 96 & 32 & 301 & 37 \\
\hline $\begin{array}{l}\text { Left sided and } \\
\text { proctitis }\end{array}$ & 51 & 20 & 164 & 62 & 122 & 41 & 337 & 41 \\
\hline Major surgery & 10 & 4 & 9 & 3 & 8 & 3 & 27 & 3 \\
\hline $\begin{array}{l}\text { Total patients by } \\
\text { centre }\end{array}$ & 261 & & 263 & & 299 & & 823 & \\
\hline Major surgery & 191 & 73 & 33 & 13 & 104 & 35 & 328 & 40 \\
\hline
\end{tabular}


624 ulcerative colitis patients referred to the Radcliffe Infirmary, Oxford, under the care of Dr Sidney Truelove which were documented and reported in $1964 .{ }^{4}$ Complete documentation from this study on all 624 patients was made available to us by Dr S Truelove and patients fulfilling the entry criteria were selected for the present study. The Radcliffe Infirmary was the only specialist referral centre for ulcerative colitis patients between 1945-1965 for the Oxford Region. These patients would comprise most but not all patients diagnosed with ulcerative colitis in the Oxford region over this time period.

The Birmingham series was drawn from a series of patients with ulcerative colitis seen at the General Hospital, Birmingham between 1944-1976. ${ }^{7}$ These were all patients with ulcerative colitis referred to $\mathrm{Dr}$ W T Cooke and Professor B N Brooke at the Queen Elizabeth and General Hospitals, Birmingham, between these years. These hospitals were the major specialist referral centres for ulcerative colitis in the West Midlands region between these years and therefore as in the Oxford series these patients comprise many but not all patients diagnosed in the West Midlands region with ulcerative colitis between these dates. Only patients with a definite diagnosis of ulcerative colitis by sigmoidoscopy, rectal biopsy, and barium enema were included in the study. All patients initially diagnosed as ulcerative colitis but subsequently found to have Crohn's disease during the course of follow up were excluded.

In the Birmingham and Stockholm groups patients with Crohn's disease had already been excluded during earlier reviews of the main series from which the cohort was drawn. There were no further exclusions during the course of follow up from the Stockholm group, and only one additional patient from the Birmingham group. In the Oxford series (which had not been reviewed in this way since 1962) 54 patients were excluded with a diagnosis of Crohn's disease, seven of whom developed colorectal cancer during the course of follow up. The number of patients contributed by each of the three centres by extent of disease and by major surgery is summarised in Table 3. There is considerable variation between the three centres in the proportion of patients developing extensive disease and also the proportion of extensive colitis patients undergoing major surgery. In the series as a whole $(n=823) 60 \%$ underwent major surgery $(n=301)$. Figure 1 shows the age distribution by centre at onset of disease.

FOLLOW UP

Of the 823 patients recruited into the study the vital status of 27 patients was not known at the end of the study (Birmingham $n=6$, Oxford $n=15$, Stockholm $n=6$ ) giving a $97 \%$ completeness of follow up.

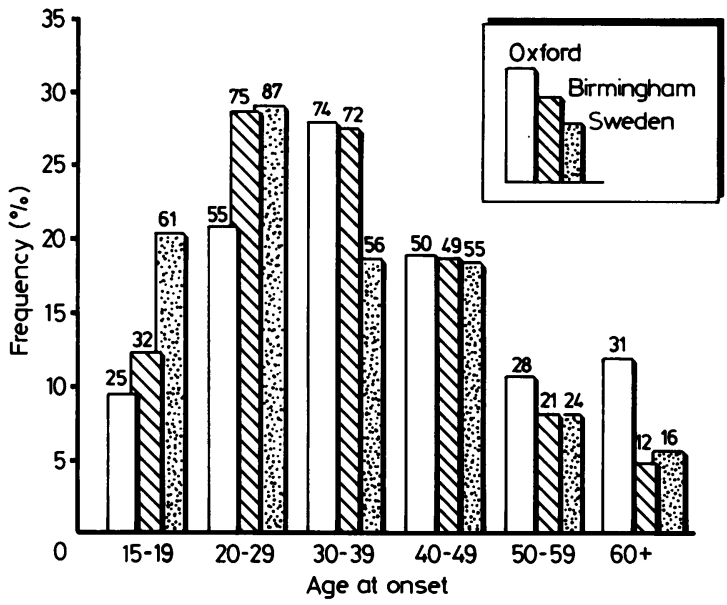

Fig. 1 Age distribution at onset of UC for all cases for Oxford, Birmingham, and Sweden referral centres. Numbers in each group appear above respective columns.

STATISTICAL ANALYSIS

Cancer morbidity in the series was examined, first, by the cohort method to obtain standardised morbidity ratios (SMR) giving estimates of the risk of cancer in the series relative to the risk in the general population. The second approach used the log rank life table method to examine and compare subgroups within the series to produce estimates of absolute risks and of relative risks between subgroups.

\section{STANDARDISED MORTALITY RATIOS}

The date of onset of disease rather than date of diagnosis was used as the entry point for the study. This enabled estimates to be made of the effect of age at onset of disease upon the colorectal cancer incidence; (by the entry criteria for the study, date of onset of disease and date of diagnosis will not differ by more than five years). Patients were recruited into the study up to five years from onset of disease to allow the inclusion of patients with milder colitis at onset of disease.

At five years from onset of disease all patients in the study had by definition been recruited and from this point person years at risk were accumulated for each patient. This approach eliminated all patients experiencing withdrawal events (death, colorectal cancer or panproctocolectomy) during the five year period of recruitment. By discarding all colorectal cancers occurring in the first five years from onset of disease any selection bias towards colorectal cancer was minimised. Figure 2 illustrates examples of nine 'sample' patients over time from onset of disease to show contributions made by different patient groups to person years at risk and the effect of discarding 


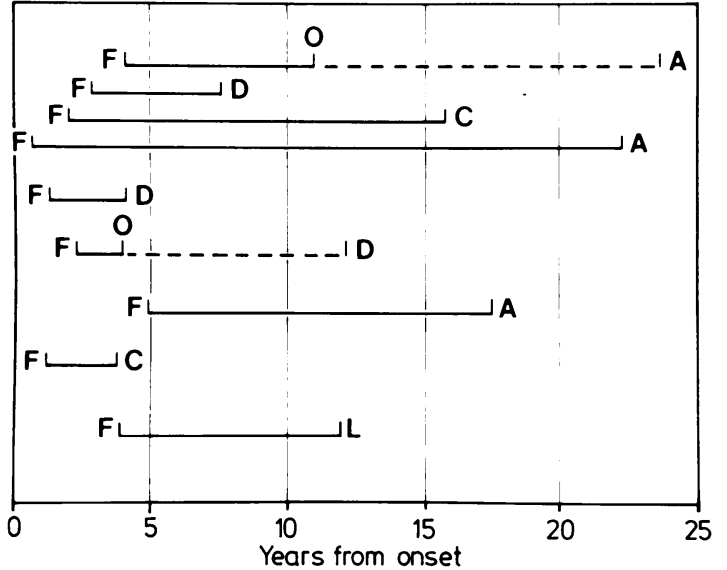

Fig. 2 Observation patterns on nine sample patients:

Colon and rectum intact-patient at risk of colorectal cancer; -... Colon and rectum removed-patient not at risk. $F=$ first seen, $O=$ operation (panproctocolectomy), $L=$ lost, $D=$ died,$C=$ cancer,$A=$ alive.

PYR accruing in the first five years from onset of disease.

Of the 823 patients recruited into the study 56 died within the first year of onset of disease and 142 underwent panproctocolectomy of whom four had colorectal cancer leaving 625 patients going forward for analysis five years from onset of disease.

Patient years at risk (PYR) were accumulated for each patient to death or the appropriate cancer or to 31 December, 1982 (Oxford and Birmingham) or 1981 (Sweden), in terms of sex, age at onset of disease and interval from onset of ulcerative colitis. Total patient years at risk by centre are shown in Table 4. The numbers of cancers that might be expected to occur during the period were obtained by applying the appropriate cancer morbidity rates to the person years at risk. Cancer morbidity rates for all sites and for colon and rectum were taken from tabulations for the West Midlands region, the Oxford region, and Sweden in consecutive volumes of Cancer Incidence in Five Continents. ${ }^{25-28}$

Table 4 Total patient years at risk by centre

\begin{tabular}{|c|c|c|c|c|}
\hline & $\begin{array}{l}\text { Birmingham } \\
(n=261)\end{array}$ & $\begin{array}{l}\text { Oxford } \\
(n=263)\end{array}$ & $\begin{array}{l}\text { Sweden } \\
(n=299)\end{array}$ & Total PYR \\
\hline Total PYR & 5636 & 5651 & 5641 & 16928 \\
\hline Colon & 2319 & 5333 & 4540 & 12192 \\
\hline Rectum & 2500 & 5318 & 4766 & 12584 \\
\hline \multicolumn{5}{|c|}{ Patient years at risk: extensive colitis } \\
\hline & $(n=209)$ & $(n=99)$ & $(n=177)$ & \\
\hline Total PYR & 4593 & 2010 & 3405 & 10008 \\
\hline Colon & 1443 & 1783 & 2410 & 5636 \\
\hline Rectum & 1619 & 1767 & 2618 & 6004 \\
\hline
\end{tabular}

Table 5 Colorectal cancer morbidity by centre: clinical data

\begin{tabular}{|c|c|c|c|c|c|}
\hline Sex & $\begin{array}{l}\text { Extent of } \\
\text { disease }\end{array}$ & $\begin{array}{l}\text { Ageat } \\
\text { onset }\end{array}$ & $\begin{array}{l}\text { Interval } \\
\text { onset to } \\
\text { cancer }\end{array}$ & $\begin{array}{l}\text { Ageat } \\
\text { cancer }\end{array}$ & Site \\
\hline \multicolumn{6}{|c|}{ Sweden } \\
\hline [M & $*$ & 45 & $1 \cdot 3$ & 47 & Left colon] \\
\hline $\mathrm{M}$ & * & 24 & $13 \cdot 7$ & 38 & Right colon \\
\hline M & * & 25 & $32 \cdot 3$ & 57 & Left colon \\
\hline $\mathrm{M}$ & * & 15 & $32 \cdot 5$ & 47 & Right colon \\
\hline $\mathrm{M}$ & * & 15 & $17 \cdot 6$ & 33 & Right colon \\
\hline 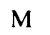 & * & 28 & $16 \cdot 1$ & 45 & Rectum \\
\hline $\mathrm{F}$ & * & 17 & $24 \cdot 1$ & 42 & Right colon \\
\hline $\mathrm{F}$ & * & 39 & $16 \cdot 1$ & 58 & Right colon \\
\hline $\mathrm{F}$ & * & 21 & $31 \cdot 7$ & 52 & Left colon+rectum (M) \\
\hline $\mathrm{F}$ & * & 33 & $11 \cdot 1$ & 45 & Colon-not specified \\
\hline $\mathrm{F}$ & * & 26 & $18 \cdot 2$ & 42 & Left colon \\
\hline |F & * & 34 & $3 \cdot 2$ & 37 & Rectum] \\
\hline $\mathrm{F}$ & * & 50 & $21 \cdot 1$ & 71 & Right colon \\
\hline $\mathrm{F}$ & * & 42 & $18 \cdot 1$ & 61 & Left colon \\
\hline$[\mathrm{F}$ & * & 50 & $3 \cdot 8$ & 54 & Left colon] \\
\hline$[\mathrm{F}$ & - & 41 & $1 \cdot 3$ & 43 & Rectum] \\
\hline \multicolumn{6}{|c|}{ Birmingham } \\
\hline F & $*$ & 16 & $25 \cdot 0$ & 41 & Rectum \\
\hline F & * & 25 & $9 \cdot 1$ & 35 & Right colon \\
\hline M & $*$ & 34 & $34 \cdot 0$ & 68 & Rectum \\
\hline$F$ & $*$ & 31 & $23 \cdot 5$ & 54 & Rectum \\
\hline M & * & 25 & $14 \cdot 2$ & 40 & Right colon \\
\hline $\mathrm{F}$ & * & 39 & $15 \cdot 3$ & 54 & Right colon \\
\hline$F$ & - & 45 & $18 \cdot 4$ & 63 & Colon-not specified \\
\hline \multicolumn{6}{|c|}{ Oxford } \\
\hline $\mathrm{F}$ & ${ }^{*}$ & 19 & $30 \cdot 4$ & 50 & Rectum \\
\hline F & * & 22 & $13 \cdot 8$ & 36 & Left colon \\
\hline$F$ & $*$ & 24 & $28 \cdot 9$ & 53 & Left colon $[\mathrm{M}]$ colon \\
\hline $\mathbf{F}$ & * & 36 & $22 \cdot 8$ & 59 & Right colon $[\mathrm{M}]$ colon \\
\hline $\mathrm{F}$ & - & 35 & $29 \cdot 2$ & 65 & Colon-not specified \\
\hline$F$ & $*$ & 25 & $6 \cdot 0$ & 31 & Right colon [M] colon \\
\hline $\mathbf{F}$ & * & 32 & $14 \cdot 1$ & 47 & Left colon \\
\hline M & * & 26 & $22 \cdot 6$ & 48 & Rectum \\
\hline M & $*$ & 34 & $18 \cdot 6$ & 52 & Left colon \\
\hline M & $*$ & 17 & $29 \cdot 1$ & 47 & Left colon \\
\hline M & - & 43 & $15 \cdot 3$ & 59 & Right colon \\
\hline M & - & 45 & $22 \cdot 0$ & 68 & Colon-not specified \\
\hline $\mathrm{F}$ & - & 53 & $13 \cdot 0$ & 67 & Left colon \\
\hline $\mathrm{F}$ & - & 55 & $20 \cdot 9$ & 76 & Right colon $[\mathrm{M}]$ colon \\
\hline $\mathbf{F}$ & * & 42 & $12 \cdot 6$ & 54 & Right colon \\
\hline
\end{tabular}

[ ] =cancer occurring within 5 years of colitis symptoms;

* = Extensive colitis; $-=$ Left sided colitis or proctitis; $\mathbf{M}=$ multiple primaries in the colon.

In the separate analyses for colon and rectal cancers patients were withdrawn at the point appropriate for the site being considered after panproctocolectomy, colectomy or proctectomy. In the Tables the expected numbers for 'all sites' have also been corrected for this procedure, those for the 'remainder' being obtained before correction.

The observed numbers of cancers were ascertained from clinical notes, death certification and from the relevant cancer registry records (Clinical table of observed cancers by centre Table 5). Differences between the observed and expected numbers of 
cancers were assessed for statistical significance on the basis of the Poisson distribution (1-tailed test) and the $95 \%$ confidence intervals of the SMR's (observed/expected number), were derived from equations for approximate limits. ${ }^{29}$

LIFE TABLE ANALYSIS

Using the logrank life table approach ${ }^{311}$ the absolute risks of colorectal cancers were computed for three factors: sex, extent of colitis and three broad age ranges. Relative risks for the subgroups within each factor were obtained and the effects on the risks after correcting for the other factor(s) were also examined.

RELATIONSHIP BETWEEN AGE AT ONSET, AGE AT CANCER AND DURATION OF DISEASE

The problem of the inter-relationship between these three factors has been examined, by considering distributions of the observed cancers in various ways and also the age specific incidence of colorectal cancers in the series.

\section{Results}

STANDARDISED MORBIDITY RATIO ANALYSES Analyses of cancer morbidity at all sites in the series are summarised in Table 6 . Overall there was a moderate excess of cancers $(p=0 \cdot 01)$ which was caused by the eight fold increase in risk of colorectal cancers. No difference between the relative risk for men and women could be detected $(t=1 \cdot 26: p=N S)$.

In extensive colitis (Table 7) very highly significant excesses of colon and rectal cancers were shown $(p=0 \cdot 001)$. Although the relative risk in the colon was higher than that for the rectum, the difference did not reach significance $(\mathrm{t}=1 \cdot 8)$ and in addition there was considerable overlap of the confidence intervals. In the remainder of series (left sided colitis and proctitis, Table 6) a moderate excess of colon

Table 6 Cancer morbidity $5+$ years from onset of ulcerative colitis (expected numbers corrected for operation): all cases

\begin{tabular}{lllllll}
\hline Site & ICD & Sex & $O$ & $E$ & $O / E$ & $P$ \\
\hline \multirow{2}{*}{ Allsites } & \multirow{2}{*}{$140-208$} & $\mathrm{M}$ & 30 & $23 \cdot 26$ & $1 \cdot 3$ & - \\
& & $\mathrm{F}$ & 46 & $30 \cdot 52$ & $1 \cdot 5$ & $\dagger$ \\
Colon+rectum & \multirow{2}{*}{153154} & $\mathrm{M}$ & 76 & $53 \cdot 78$ & 1.4 & $\dagger$ \\
& & $\mathrm{F}$ & 12 & $1 \cdot 92$ & $6 \cdot 3$ & $\ddagger$ \\
Sites other than & & $\mathrm{T}$ & 35 & $2 \cdot 36$ & $9 \cdot 7$ & $\ddagger$ \\
colon+rectum & & $\mathrm{M}$ & 18 & $21 \cdot 34$ & $0 \cdot 8$ & - \\
& & $\mathrm{F}$ & 23 & $28 \cdot 16$ & $0 \cdot 8$ & - \\
& & $\mathrm{T}$ & 41 & $49 \cdot 30$ & $0 \cdot 8$ & - \\
\hline
\end{tabular}

${ }^{*} \mathrm{p}=0 \cdot 05 ; \uparrow \mathrm{p}=0 \cdot 01 ; \neq \mathrm{p}=0 \cdot 001 ; \mathrm{O}=$ observed number $; \mathrm{E}=$ expected number.
Table 7 Colorectal cancers

\begin{tabular}{lllll}
\hline & \multicolumn{3}{l}{ Observed and expected numbers } & \\
\cline { 2 - 4 } & Observed & Expected & O/E & $p$ \\
\hline Extensive colitis & 29 & $1 \cdot 51$ & $19 \cdot 2$ & $\dagger$ \\
Colon 22 & & 0.90 & 24.4 & $\dagger$ \\
Rectum 7 & $0 \cdot 61$ & $11 \cdot 5$ & $\dagger$ \\
Left sided colitis and proctitis & & & \\
Colon & 6 & 1.68 & $3 \cdot 6$ & $*$ \\
Rectum & 0 & 1.07 & - & \\
Total series & 35 & 4.28 & $8 \cdot 2$ & $\dagger$ \\
\hline
\end{tabular}

${ }^{*} \mathrm{p}=0 \cdot 01 ; \dagger \mathrm{p}=0 \cdot 001$.

cancers was found $(p=0 \cdot 01)$ but no effect in the rectum could be shown.

Relative risks of colorectal cancers for five year periods from onset of extensive colitis are shown in Table 8 . Over the period $10-30$ years the results are consistent with a constant relative risk over time. The excess at five to nine years was only of marginal significance on a 1 -tailed test and the $95 \%$ confidence intervals suggests that this result was not significantly different from a relative risk of $1 \cdot 0$. The apparent sharp increase in risk at 30 to 40 years is based on small numbers with very wide confidence limits about the SMR.

When the relative risk by age at onset was considered, a decrease in risk with increasing age at onset was found (Table 9, Fig. 3). The excesses were highly significant in those under 40 years of age at onset $(p=0 \cdot 001)$ and the risk was also increased in those over the age of 40 years but to a lesser extent. Although the cumulative relative risks (sum of observed numbers/sum of expected) for the age ranges (Fig. 3) show some variation, the more stable line for all ages combined is suggestive of an increasing risk up to 20 years. The further increase at 30-35 years is the result of six cases noted previously (Table

Table 8 Colorectal cancers by time from onset of ulcerative colitis (extensive colitis: men+women: three centres)

\begin{tabular}{lllllr}
\hline Yearfrom onset & Observed & Expected & $O / E$ & $p$ & $95 \% C I$ \\
\hline $0-$ & - & - & - & - & \\
$5-$ & 2 & $0 \cdot 294$ & $6 \cdot 8$ & $*$ & $0 \cdot 8-24 \cdot 6$ \\
$10-$ & 6 & $0 \cdot 324$ & $18 \cdot 5$ & + & $6 \cdot 8-40 \cdot 3$ \\
$15-$ & 7 & $0 \cdot 328$ & $21 \cdot 3$ & $\dagger$ & $8 \cdot 6-44 \cdot 0$ \\
$20-$ & 5 & $0 \cdot 257$ & $19 \cdot 5$ & + & $6 \cdot 3-45 \cdot 4$ \\
$25-$ & 3 & $0 \cdot 179$ & $16 \cdot 8$ & + & $3 \cdot 4-49 \cdot 0$ \\
$30-$ & 6 & $0 \cdot 107$ & $56 \cdot 1$ & + & $20 \cdot 5-122 \cdot 1$ \\
$35+$ & 0 & $0 \cdot 023$ & 0 & - & \\
\hline
\end{tabular}

${ }^{*} p=0 \cdot 05 ; \mathrm{\dagger}=0 \cdot 001$. 


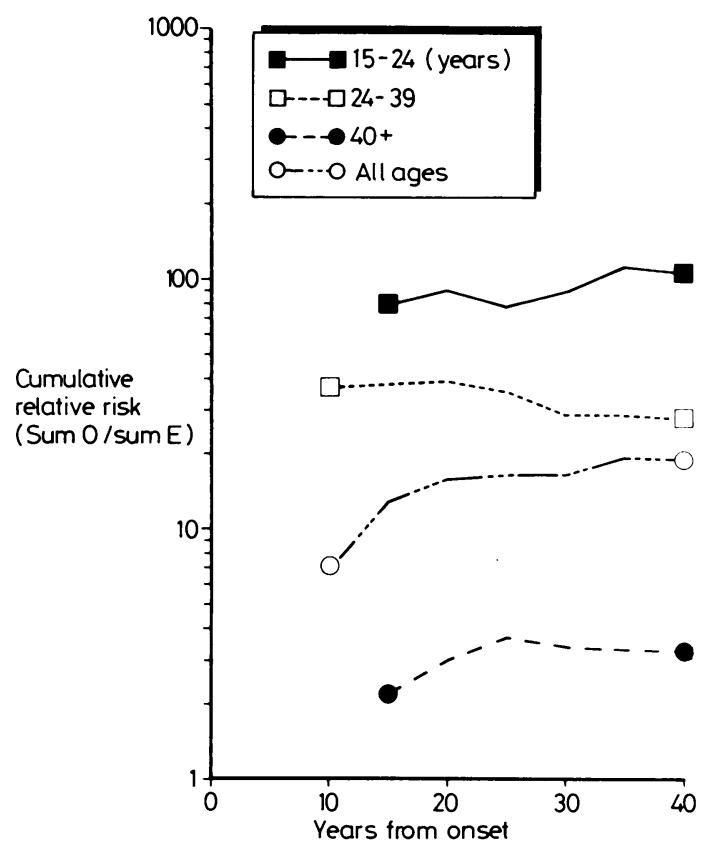

Fig. 3 Cumulative relative risk (sum observed $(O) /$ sum expected $(E)$ ) of colorectal cancer by age at onset of disease in three broad age bands at onset and all ages (log scale).

8), five of which occurred in patients aged 15-24 years at onset of disease.

LOGRANK ANALYSIS

The cumulative probability of developing colorectal cancer in extensive colitics was compared with that in the remaining patients with left sided colitis (Fig. 4) or with an unknown extent of disease. The difference between the two groups was highly significant $\left(\chi_{(1)}^{2}=22 \cdot 66, p=0 \cdot 001\right)$ the risk in extensive colitis being 6.0 times that in the remainder after adjusting for age and sex.

Three factors were tested in the group of extensive colitics: (1) referral centre, (2) sex, and (3) age at onset of disease. No significant difference between centres could be shown $\left(\chi_{(2)}^{2}=0.33\right)$ after adjusting for age and sex (Fig. 5).

Table 9 Colorectal cancers by age at onset of ulcerative colitis (extensive colitis: men + women: three centres)

\begin{tabular}{lllrlc}
\hline Ageat onset & Observed & Expected & O/E & $p$ & $95 \%$ CI \\
\hline $15-24$ & 12 & $0 \cdot 112$ & $107 \cdot 1$ & $*$ & $55 \cdot 3-187 \cdot 2$ \\
$25-39$ & 14 & $0 \cdot 502$ & $27 \cdot 9$ & $*$ & $15 \cdot 2-46 \cdot 8$ \\
$40+$ & 3 & $0 \cdot 898$ & $3 \cdot 3$ & - & $0 \cdot 7-9 \cdot 8$ \\
Total & 29 & $1 \cdot 512$ & $19 \cdot 2$ & $*$ & $12 \cdot 8-27 \cdot 5$ \\
\hline
\end{tabular}

${ }^{*} \mathrm{p}=0.001$.

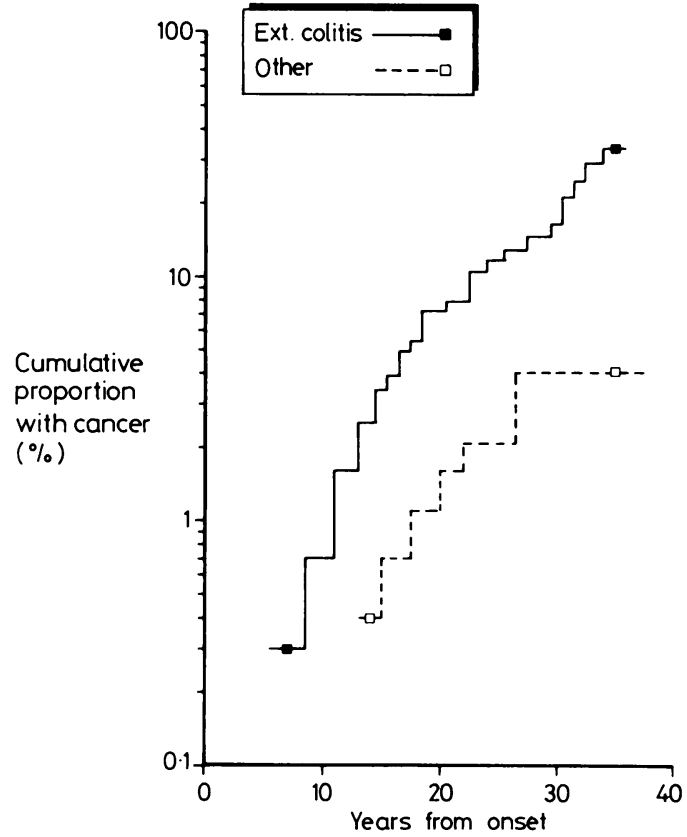

Fig. 4 Cumulative proportion of patients with colorectal cancers by extent of disease: Extensive colitis and remainder of series. Three centres combined (log scale).

The data were, therefore, combined to test the effect of sex. Although the risk was marginally lower in men, again the difference between men and women did not achieve statistical significance $\left(\chi_{(1)}^{2}=0.45\right)$ after adjusting for age (Fig. 6).

When considering age as the main factor, no significant difference between the three age ranges could be shown $\left(\chi_{(2)}^{2}=0 \cdot 71\right.$, after adjusting for sex $)$, the risks in the younger groups, relative to that in the third group (age 40+ years), were 1.6 fold (age 15-24 years) and 1.7 fold (age 25-39) (Fig. 7).

As little effect of centre, sex or age on the absolute risk could be detected, the best estimate of cumulative risk can be summarised from the graph for extensive colitics in Figure 8. The points at five year intervals are given in Table 10 , together with the numbers of patients entering each interval from onset and the $95 \%$ confidence intervals of the estimate. At 20 years from onset the estimated proportion of patients with colorectal cancer was 7.2\% (3.6$10 \cdot 8 \%)$ and at 30 years was $16 \cdot 5 \%(9 \cdot 0-24 \cdot 0 \%)$. The doubling in risk between 30 and 35 years again reflects the contribution of five cancers in the group at age 15-24 years at onset of disease.

RELATIONSHIP BETWEEN AGE AT ONSET, AGE AT CANCER AND DURATION OF DISEASE

The distribution of the 29 colorectal cancers in 


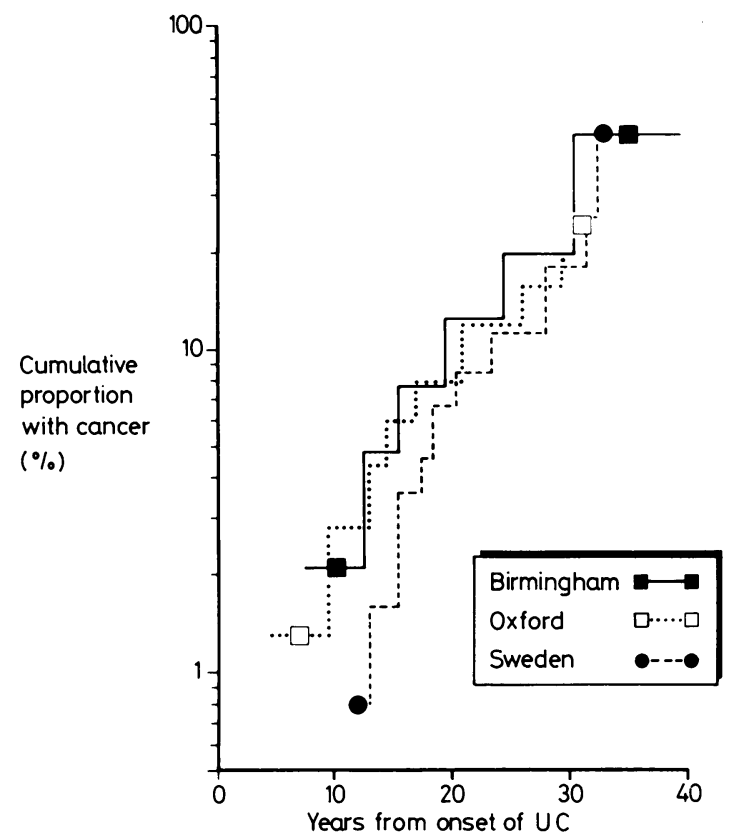

Fig. 5 Extensive colitis. Cumulative proportion of patients with colorectal cancers by referral centre (log scale).

patients with extensive colitis in terms of age at onset, age at cancer and interval from onset to cancer are shown in Figure 9 the majority of cancers occurred in patients with onset of disease before 35 years of age, only once cancer occurring in a patient with onset of disease after 45 years. The interval between onset to cancer in most cases was between 10-24 years but six cancers did occur 30 or more years after onset of disease. Figure 9 illustrates, when considering interval from onset to cancer, and age at cancer, that age at cancer gave a more 'normal' distribution than interval from onset to cancer with a peak incidence of cancer occurring at around 50 years of age.

This finding led us to examine the relationship

Table 10 Absolute cumulative frequency of colorectal cancers (extensive colitis: men + women: three centres)

\begin{tabular}{|c|c|c|c|c|}
\hline Years from onset & $\begin{array}{l}\text { Patients } \\
\text { (n) }\end{array}$ & $\begin{array}{l}\text { Colorectal } \\
\text { cancers }\end{array}$ & $\begin{array}{l}\text { Absolute } \\
\text { cumulative } \\
\text { frequency } \\
(\%)\end{array}$ & $95 \% \mathrm{CI}$ \\
\hline 5 & 308 & 2 & $0 \cdot 0$ & - \\
\hline 10 & 244 & 6 & 0.7 & $0-1 \cdot 1$ \\
\hline 15 & 195 & 7 & $3 \cdot 4$ & $1 \cdot 0-5 \cdot 8$ \\
\hline 20 & 132 & 5 & $7 \cdot 2$ & $3 \cdot 6-10 \cdot 8$ \\
\hline 25 & 73 & 3 & $11 \cdot 6$ & $6 \cdot 4-16 \cdot 8$ \\
\hline 30 & 36 & 6 & $16 \cdot 5$ & $9 \cdot 0-23 \cdot 96$ \\
\hline 35 & 12 & 0 & $33 \cdot 4$ & $19 \cdot 26-47 \cdot 54$ \\
\hline
\end{tabular}

Table 11 Mean duration of ulcerative colitis before cancer and mean age at cancer for 29 colorectal cancers in extensive colitis

\begin{tabular}{llll}
\hline $\begin{array}{l}\text { Age at onset of } \\
\text { UC }\end{array}$ & $n$ & $\begin{array}{l}\text { Mean interval between } \\
\text { UCand cancer }(\text { years) }\end{array}$ & $\begin{array}{l}\text { Mean at at } \\
\text { cancer }\end{array}$ \\
\hline $15-19$ & 6 & $26 \cdot 7$ & $44 \cdot 2$ \\
$20-24$ & 5 & $23 \cdot 8$ & $46 \cdot 3$ \\
$25-29$ & 7 & $17 \cdot 1(20 \cdot 8)^{*}$ & $44 \cdot 6(48 \cdot 3)^{*}$ \\
$30-34$ & 5 & $20 \cdot 1$ & $52 \cdot 6$ \\
$35-39$ & 3 & $18 \cdot 3$ & $55 \cdot 8$ \\
$40-44$ & 2 & $15 \cdot 7$ & $58 \cdot 2$ \\
$45-49$ & 0 & - & - \\
$50-54$ & 1 & {$[21 \cdot 1]$} & {$[72 \cdot 6]$} \\
\hline
\end{tabular}

${ }^{*}=$ means after excluding two patients with intervals $6 \cdot 0$ and $9 \cdot 9$ years.

between interval from onset to cancer for individual age groups at onset of disease to determine whether there was a negative relationship between these factors. This proved to be the case (Table 11). With one exception (age agoups 25-29 years) the mean interval fell regularly from around 27 years for onsets at $15-19$ years of age to 16 years for those at $40-44$ years. By adding mean age at onset - that is, 17.5 years for the first group, to the mean interval, a mean age at cancer was obtained and is shown in the last column of Table 11 .

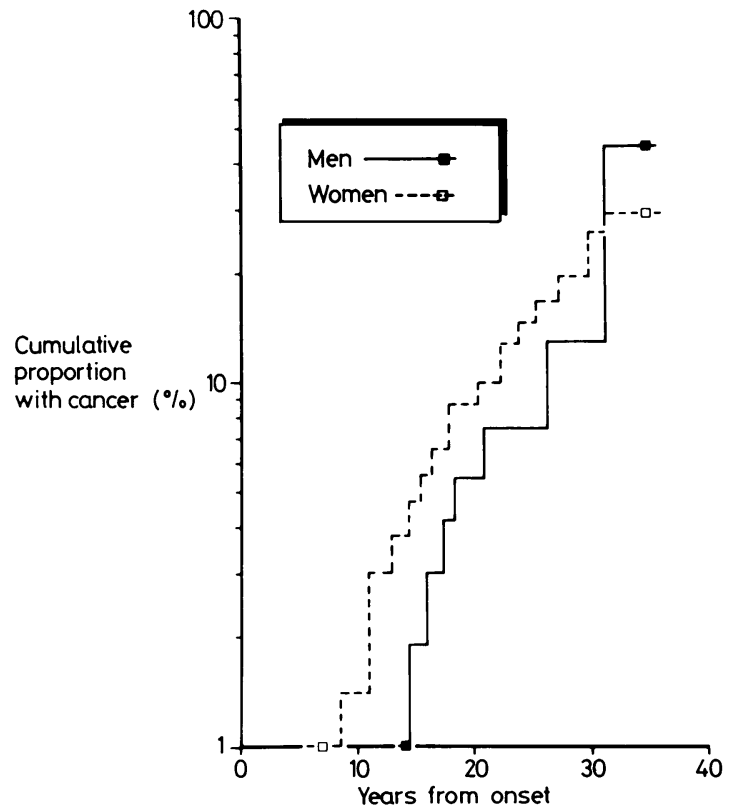

Fig. 6 Extensive colitis. Cumulative proportion of patients with colorectal cancers by sex. All centres combined (log scale). 


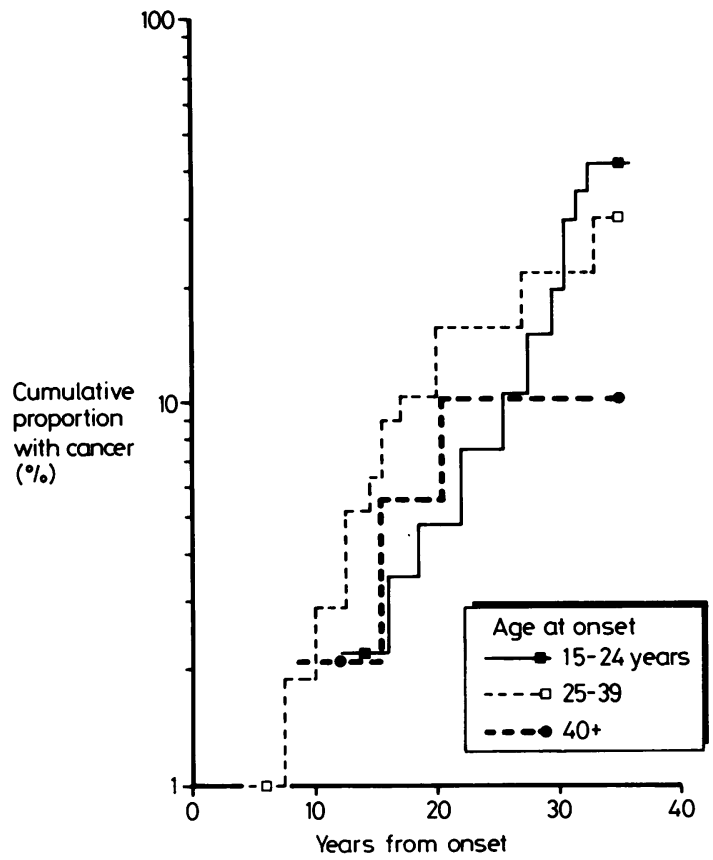

Fig. 7 Extensive colitis. Cumulative proportion of patients with colorectal cancers by age at onset of UC in three broad age bands.

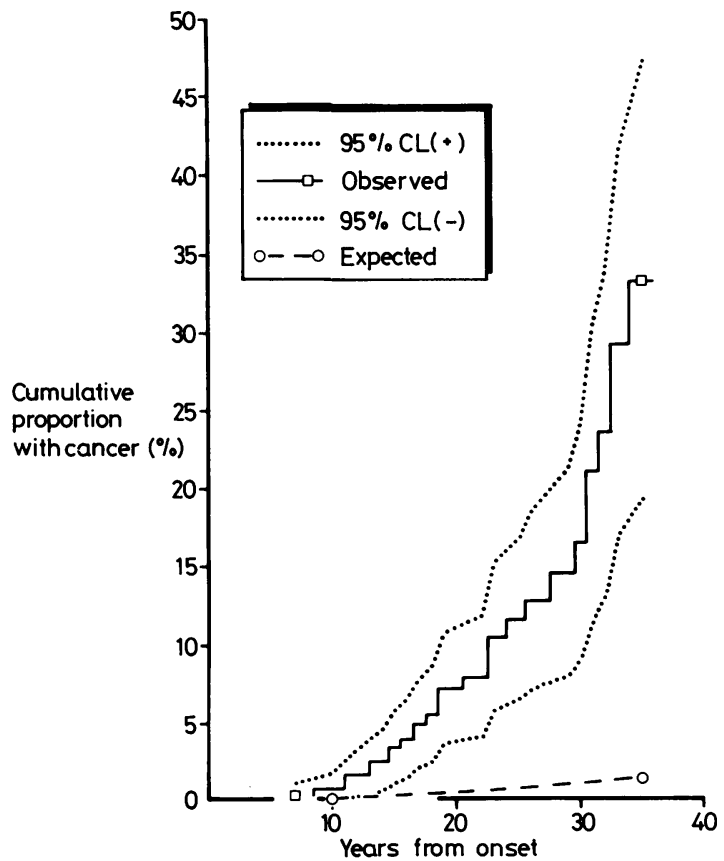

Fig. 8 Extensive colitis: cumulative proportion of patients with colorectal cancers, combined for sex, age at onset and referral centre (arithmetic scale).
This apparent negative correlation between age at onset and duration of disease was examined in the first instance by a simple scattergram for the 29 cases. With division at the medians a significant effect $\left(\chi_{(1)}^{2}=4.386, p=0.05\right)$ of negative correlation was obtained, but on formal correlation analysis, the correlation coefficient did not quite reach the $5 \%$ significant level $(r=0 \cdot 332, t=1 \cdot 83)$. Inspection of the relatively low mean interval (17.12 years) for age group 25-29, it was found that two patients had recorded intervals of six years and 9.9 years. In the first patient the cancer was an incidental finding at panproctocolectomy for ulcerative colitis and in the second patient the colon cancer was stage 4 at diagnosis. These two patients also appeared as obvious outliers on the scattergram. If these two cases are excluded the mean interval for the 25-29 year age-group rose to 20.8 years and the mean age at cancer to 48.3 years thus completing the linear effect suggested by the remaining five points in Table 11 . Repeating the correlation analysis on 27 cases now produced a significant coefficient $(\mathrm{r}=-0.512$, $\mathrm{t}=2 \cdot 98, \mathrm{p}=0 \cdot 01$ ).

As half the expected number of cancers $(0 \cdot 8)$ for these extensive colitic patients were predicted to occur at age 60 years or above, the one patient with cancer with onset of ulcerative colitis after age 50 might be assumed to satisfy this expectation. Thus with onset of ulcerative colitis spanning a 35 year age range, the mean ages at cancer were contained within a 14 year age range.

As the numbers of cancers occurring at different ages might be dependent on the age structure of series at a particular point in follow up the age specific rates were examined (Table 12) and found also to peak around 50-54 years and then fall off.

\section{Discussion}

We feel that this cohort study presents the best estimates presently available of the colorectal cancer incidence in ulcerative colitis. The collaborative

Table 12 Age specific rates of colorectal cancers in extensive colitis

\begin{tabular}{lll}
\hline Age & $n$ & Rate $\left(\right.$ per $10^{3}$ per year) \\
\hline $25-29$ & - & - \\
$30-34$ & 2 & $4 \cdot 1$ \\
$35-39$ & 3 & $5 \cdot 5$ \\
$40-44$ & 4 & $7 \cdot 1$ \\
$45-49$ & 6 & $12 \cdot 2$ \\
$50-54$ & 8 & $18 \cdot 4$ \\
$55-59$ & 3 & $8 \cdot 5$ \\
$60-64$ & 1 & $4 \cdot 1$ \\
$65-69$ & 1 & $5 \cdot 6$ \\
$70+$ & 1 & $5 \cdot 3$ \\
\hline
\end{tabular}



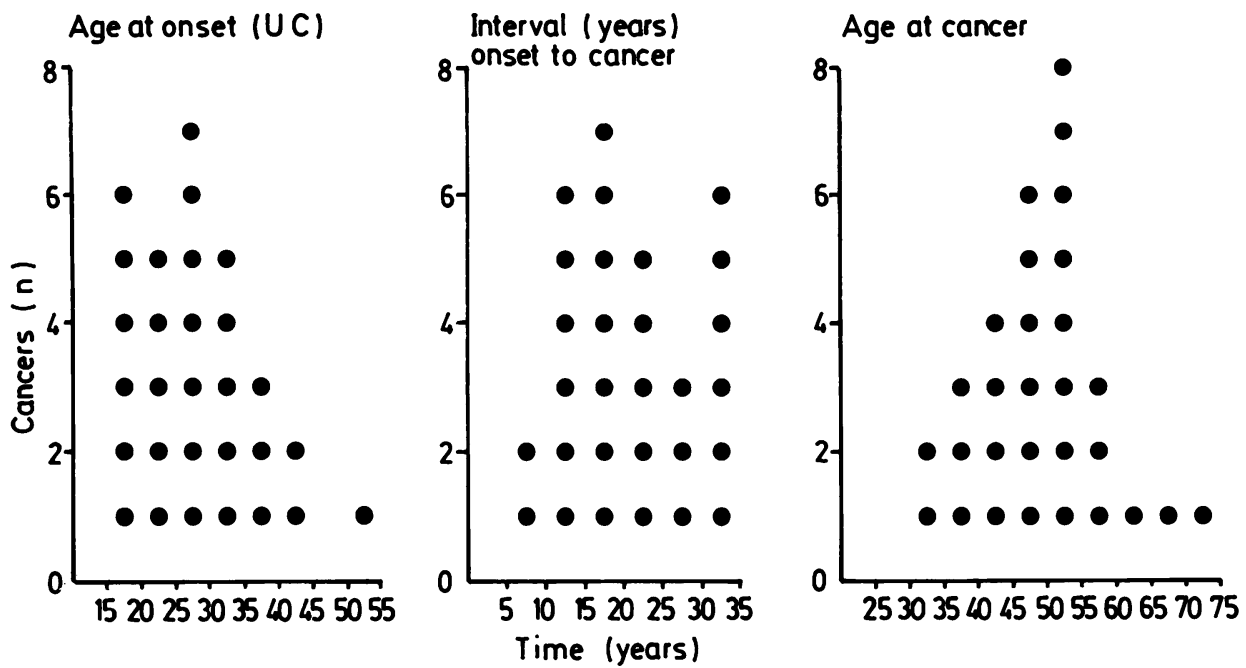

Fig. 9 Extensive colitis. Distribution of 29 observed colorectal cancers by age at onset, interval from onset to cancer and age at cancer.

approach combined data from three specialist centres (Birmingham, Oxford and Stockholm) possessing good documentation on all ulcerative colitis patients for more than 40 years has resulted in a study giving sufficient numbers of patients and length of follow up to produce results with reasonable confidence limits.

We do not consider our present study group was biased in terms of cancer morbidity in that if we consider cancer morbidity at all sites other than colon and rectum the relative risk approaches unity (observed $=41$, expected $=49 \cdot 5, \mathrm{O} / \mathrm{E}=0 \cdot 8$ ).

Also the absolute cancer incidence by centre contributing cases was almost identical (Fig. 5).

CANCER INCIDENCE IN EXTENSIVE COLITIS

We show in this study using onset of disease as the starting point a considerably lower probability of developing colorectal cancer in extensive colitis than had been suggested from previous studies particularly studies based on hospital series (Table 1). If we compare our results with the only other cohort study (Table 2) ${ }^{23}$ reviewing a comparable number of extensive colitic patients the predicted risk at 20 years from onset of disease was $24 \%$ in Goteburg group (CI $11 \cdot 0-37 \cdot 4$ ) and $7 \cdot 2 \%$ (CI 3.6-10.8) in our present study. The upper confidence limits of our results do not overlap with the lower limits in the Goteburg study.

IMPLICATIONS OF THE RESULTS CONCERNING AETIOLOGY OF COLORECTAL CANCER IN ULCERATIVE COLITIS

The underlying assumption of all studies designed to determine the cancer incidence in ulcerative colitis including the present study has been that the disease process itself was in some way implicated in the initiation/promotion process. All studies have therefore analysed their data either from onset of disease or date of diagnosis in order to determine the probability of developing cancer in relation to dura-

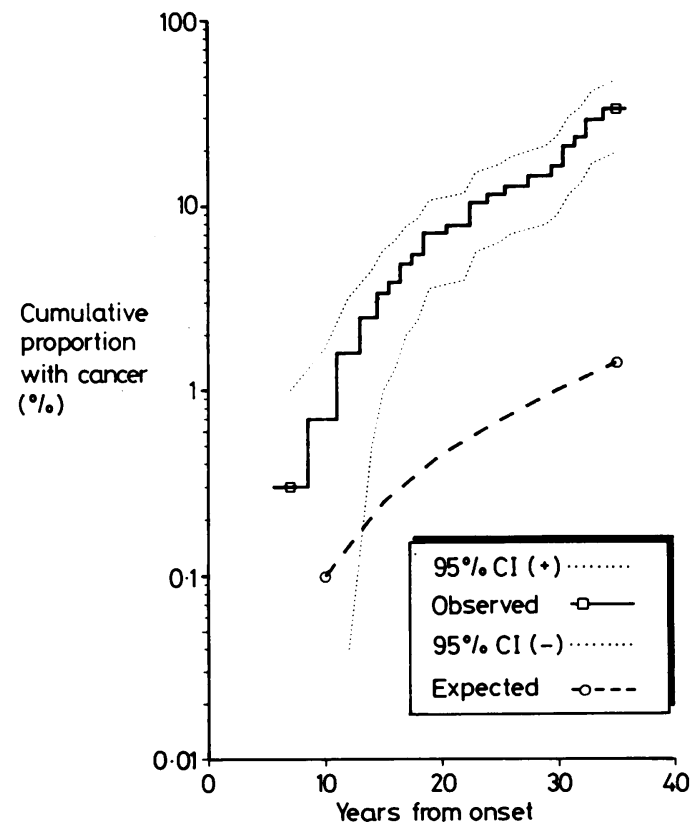

Fig. 10 Extensive colitis. Cumulative proportion of patients with colorectal cancers, combined for sex, age at onset and referral centre (log scale). 
tion of disease. Our present study was designed to be analysed the same way.

It has always been somewhat puzzling that if the inflammatory process is implicated in the initiation/ promotion of cancer that patients with severe left sided colitis or proctitis over long time periods are at little or no more at risk of developing colorectal cancer than the general population.

The four fold increase in relative risk in patients with left sided disease (in our present study) may represent a real increase in risk in this subgroup. It may equally well, however, be a reflection of undiagnosed extensive colitis patients remaining in the left sided disease group. The selection of 'extensive colitis' patients as a subgroup of the main series is a somewhat arbitrary procedure depending to a large extent upon whether a recent barium enema has been carried out, upon the expertise of the radiologist involved, and upon the method used to define extensive colitis. Greenstein et $^{\mathrm{al}} \mathrm{l}^{\mathrm{s}}$ also found a small increased risk in left sided colitis to which the same reservations would apply.

The clinical data of the colorectal cancers in our study (Table 5) suggested a considerable variation in the intervals between onset of disease to cancer but much less variation in the actual age patients developed cancer, most patients developing cancer around 50 years of age. This is summarised in Figure 9 which shows the cancers in extensive colitis patients by age at onset of disease, interval from onset to cancer and age at cancer. The 'age at cancer' gives a less skewed distribution than 'interval from onset to cancer'.

When we therefore examined (a) the mean interval between onset and cancer (b) the mean age at cancer by age at onset of disease in 5 year age bands (Table 11) a decreasing mean interval from onset to cancer with increasing age at onset of disease was found. The age specific rates for cancer also increased up to age 50 years and decreased thereafter.

An alternative hypothesis to the inflammatory process itself promoting cancer which would fit our results would be to postulate that if a patient with ulcerative colitis is going to develop colorectal cancer he/she will be at maximum risk of developing the cancer around 50 years of age regardless of age at onset or duration of disease. Duration of disease may only appear to be related to the age at cancer in that these two factors are inevitably linked. The increasing age specific risk up to the age of 50 years is similar in pattern to that found in the general population but the risk is at a much higher level. This relationship is well shown by expressing the observed and expected probabilities (Fig. 8) on a log scale (Fig. 10).

This pattern is suggestive of a group of patients with an increased susceptibility for colorectal cancer, possibly genetically determined, but relating to the same initiators/promotors as those present in the general population.

It could be that the peak for age at cancer at 50 years is an artefact of the length of follow up, however, many of the younger entrants only just approaching 50 years of age. This explanation is unlikely as there were sufficient person years at risk after age 50 to show a fall in age specific rates. On reviewing other reported series to determine whether similar patterns had been observed for age at cancer the information given was too limited to be useful.

Our series was confined to patients with onset of disease at age 15 years and above and did not include childhood onset ulcerative colitis. It is not clear from other reported series whether the cancers observed had developed in patients with childhood onset ulcerative colitis. There is evidence that these patients may be a separate group with a peak cancer incidence at a younger age. ${ }^{31}$

\section{CLINICAL IMPLICATIONS}

If the maximum risk of colorectal cancer in ulcerative colitis patients is around age 50 and not dependent upon duration of disease it would be more rational to base screening procedures upon the actual age of the patient rather than the duration of disease. In practice there is probably very little difference in the workload whichever approach is used. It can be seen from Figure 9 that (given the screening procedure were $100 \%$ effective) all but two of the cancers would be detected by screening all extensive colitis patients 10 years from onset of disease. If screening were carried out on all extensive colitis patients between the ages of 30-60 years all but three of the cancers would have been detected. This second approach could possibly save unnecessary screening in patients with early onset of disease.

More supportive evidence from our results in relation to age at cancer in adult onset ulcerative colitis would need to be adduced from other studies before any changes in the basis of screening should be considered.

We gratefully acknowledge the financial support of the Cancer Research Campaign for this study. We thank Dr J Peto, Institute of Cancer Research, Sutton, Surrey for the use of the MANYEARS computer programme. We thank D Pope for the computer graphics.

\section{References}

1 Butt JH, Lennard-Jones JE, Ritchie JK. A practical approach to the risk of cancer in inflammatory bowel disease. Med Clin North Am 1980; 64: 1203-20. 
2 de Dombal FT, Watts J, Watkinson G, et al. Local complications of ulcerative colitis: Stricture, pseudopolyposis and carcinoma of the colon and rectum $\mathrm{Br}$ Med J 1966; i: 1442-7.

3 McDougall I. The cancer risk in ulcerative colitis. Lancet 1964 ii; 655-9.

4 Edwards FC, Truelove SC. The course and prognosis of ulcerative colitis. Gut 1964; 4: 299-315.

5 Greenstein AJ, Sachar DB, Smith H, et al. A comparison of the cancer risk in Crohn's disease and ulcerative colitis. Cancer 1981; 48: 2742-5.

6 Lennard-Jones JE, Morson BC, Ritchie JK, et al. Cancer surveillance in ulcerative colitis. Experience over 15 years. Lancet 1983; ii: 149-52.

7 Prior P, Gyde SN, Macartney JC, et al. Cancer morbidity in ulcerative colitis. Gut 1982; 23: 490-7.

8 Katzka I, Brody R, Morris E, Katz S. Assessment of colorectal cancer risk in patients with ulcerative colitis. Experience from a private practice. Gastroenterology 1983; 85: 22-9.

9 Bonnevie O, Riis P, Anthonisen P. An epidemiological study of ulcerative colitis in Copenhagen County. Scand $J$ Gastroenterol 1968; 3: 432-8.

10 Evans JG, Acheson ED. An epidemiological study of ulcerative colitis and regional enteritis in the Oxford area. Gut 1965; 6: 311-24.

11 Linden G, Noller C. Ulcerative colitis in Finland. II. One year incidence in all hospitals. Dis Colon Rectum 1971; 14: 264-6.

12 Wigley RD, MacLaurin BP. A study of ulcerative colitis in New Zealand showing a low incidence in Maoris. $\mathrm{Br}$ Med J 1962; ii: 228-31.

13 Monk M, Mendeloff AL, Siegel CI, Lilienfeld A. An epidemiological study of ulcerative colitis and regional enteritis among adults in Baltimore. 1. Hospital incidence and prevalence 1960-1963. Gastroenterology 1967; 53: 198-210.

14 Sinclair TS, Brunt PW, Ashley N, Mowat G. Nonspecific proctocolitis in North Eastern Scotland: A community study. Gastroenterology $1983 ; 85$ : 1-11.

15 Nefzger MD, Acheson ED. Ulcerative colitis in the US Army. Gut 1963; 4: 183-92.

16 Edwards FC, Truelove SC. The course and prognosis of ulcerative colitis. Part III and IV Complications and carcinoma of the colon. Gut 1964; 5: 1-22.

17 Watts J McK, de Dombal FT, Watkinson G, et al. Long term prognosis of ulcerative colitis. $B r$ Med $J$ 1966; i: 1447-53.

18 Jalan KN, Prescott RJ, Sircus W, et al. An experience of ulcerative colitis. II. Short term outcome. III. Long term outcome. Gastroenterology 1970; 59: 598-608.

19 Bonnevie O, Binder V, Anthonisen P, et al. The prognosis of ulcerative colitis. Scand J Gastroenterol 1974; 9: 81-91.

20 Gilat R, Ribak J, Benaroya Y, et al. Ulcerative colitis in the Jewish Population of Tel-Aviv Gastroenterology 1974; 66: 335-42.

21 Storgaard L, Bischoff N, Hendriksen FE, et al. Survival rates in Crohn's disease and ulcerative colitis. Scand J Gastroenterol 1979; 14: 225-30.

22 Hendriksen C, Kreiner S, Binder V. Long term prognosis in ulcerative colitis - based on results from a regional patient group from the County of Copenhagen. Gut 1985; 26: 158-63.

23 Kewenter J, Ahlman H, Hulten L. Cancer risk in extensive colitis. Ann Surg 1978; 188: 824-27.

24 Ritchie JK. Ileostomy and excisional surgery for chronic inflammatory disease of the colon: a survey of one hospital region. Part I. Results of complications of surgery. Part II. Health of ileostomists. Gut 1971; 12: 528-40.

25 Doll R, Payne $\mathrm{P}$, Waterhouse JAH. Cancer incidence in five continents. Vol I. Berlin: Springer Verlag, 1966.

26 Doll R, Muir C, Waterhouse JAH. Cancer incidence in five continents. Vol II. Berlin: Springer Verlag, 1970.

27 Waterhouse JAH, Muir C, Correa P, Powell J. Cancer incidence in five continents. Vol III. Lyon: International Agency for Research in Cancer, 1976.

28 Waterhouse JAH, Muir C, Shanmuggarathan K, Powell $\mathrm{J}$. Cancer incidence in five continents. Vol IV. Lyon: International Agency for Research in Cancer, 1982.

29 Rothman KJ, Boice JD Jr. Epidemiological analyses with a programmable calculation. NIH Publication no 79-1649. Washington DC: US Government Printing Office, 1979.

30 Peto R, Pike MC, Armitage P, et al. Design and analysis of randomised clinical trials requiring prolonged observation of each patient. II. Analysis and examples. Br J Cancer 1977; 35: 1-39.

31 Devroede G, Taylor W, Sauer W, et al. Cancer risk and life expectancy of children with ulcerative colitis. N Engl J Med 1971; 285: 17-21. 